The results of the research into the electrical properties of the "water in castor oil" emulsion, which make it possible to substantiate the technology of castor oil purification from plant impurities and water in an electric field, were presented.

The experimental studies of the electrical properties of the "water in castor oil" emulsion revealed the dependences of specific resistance to direct and alternating currents and dielectric loss angle tangent on the temperature and water content. It was proved that the active component of specific resistance to the suspension "water in castor oil" on AC is smaller than resistance to $D C$. That is why, at the temperature of $80{ }^{\circ} \mathrm{C}$ and water content of $2 \%$, heat release on $A C$ is $10 \%$ higher than the heat release on DC. According to this, it is advisable to perform the process of castor oil purification from plant impurities and water residues on AC. This makes it possible to obtain additional heat release and thereby compensate for heat losses for the vaporization of flotation bubbles, which leads to the stable process of flotation purification. A comparison of the magnitudes of polarization losses and losses of end-to-end electrical conductivity for pure oil indicates their identical order. The addition of water leads to an increase in polarization losses due to the structural and dipole polarization of water as a polar fluid. Due to this, from the theoretical point of view, it can be argued about additional local heat release on finely dispersed water drops in the quantity, which can ensure the compensation for the heat needed for vaporization. According to this, vaporization does not require indirect heating of the electrode area from an external source at the expense of thermal conductivity.

The obtained results of the experimental research make it possible to substantiate the technological and structural parameters of the electro-technological complex of castor oil purification in the electric field of the cylindrical system of electrodes

Keywords: electric field, castor oil, specific resistance, dielectric loss angle tangent

ㅁ
UDC621.3:665.335.5

DOI: $10.15587 / 1729-4061.2020 .210312$

\title{
ELECTRICAL PROPERTIES OF "WATER IN CASTOR OIL" EMULSION
}

I. Nazarenko

Doctor of Technical Sciences, Professor*

*Department of Electrotechnology and Thermal Processes Dmytro Motornyi Tavria State Agrotechnological University B. Khmelnytskoho ave., 18, Melitopol, Ukraine, 72312 E-mail: ihor.nazarenko@tsatu.edu.ua

O. Dide n ko

Postgraduate Student, Assistant* E-mail: sdidenko76@i.ua

O. Lo bod a

$\mathrm{PhD*}$

E-mail: aleks.loboda27@gmail.com

R. K u s h l y k

$\mathrm{PhD}$, Senior Lecturer*

E-mail: kushlykr@gmail.com

L. Chervinsk y

Doctor of Technical Sciences, Professor

Department of Electrical Engineering, Electromechanics and

Electrical Technology

National University of Life

and Environmental Sciences of Ukraine Heroyiv Oborony str., 15, Kyiv, Ukraine, 03041

E-mail: Ichervinsky@gmail.com

\section{Introduction}

Natural vegetable oils are the most important components of raw materials in the production of cosmetics and components for skin treatment. In medicine, oil emulsions and creams are made from different vegetable oils (castor, almond). Glycerin and fatty acids are obtained from vegetable oils. Valuable multi-protein saturated feeds are wastes - oil cake and groats that are used for the production of feeds. In the future, due to the growing environmental problems and the need for products on a biological basis to replace synthetic raw materials, castor oil can be used in many industries [1].

In recent years, the products of plant oil processing have been used increasingly often as an alternative to fuels for diesel engines, which have better environmental characteristics than petroleum fuels. Ricin (castor) oil is a valuable product with specific properties. From 50 to $55 \%$ of oils are accumulated in castor seeds. Castor oils contain about $90 \%$ of glycerides of castor acid, which was not found in other oils.
Copyright (C) 2020, I. Nazarenko, O. Didenko, O. Loboda, R. Kushlyk, L. Chervinskiy This is an open access article under the CC BY license (http://creativecommons.org/licenses/by/4.0)
Castor oil belongs to the group of nondrying oils, it is very viscous, weakly dissolved in gasoline and other organic solvents, does not freeze at low temperatures (minus $12-18{ }^{\circ} \mathrm{C}$ ), flames up at high temperatures (plus $300-310^{\circ} \mathrm{C}$ ). That is why it is an unsurpassed lubricant when it comes to quality, especially for aviation engines and mechanisms operating under complicated conditions of the north.

The oil is obtained from castor seeds by hot or cold pressing. Hot pressing ensures greater yield of oil, but its quality is worse, because poisonous substances, such as ricin and ricinin, get to the oil from seeds. That is why this oil is suitable only for technical needs. To obtain a high-quality product, the oil is to be purified. Existing traditional purification methods (filtration, settling, etc.) do not make it possible to get a high-quality product or are energy- and resource-consuming. That is why it is urgent to find new technologies for castor oil purification from plant impurities, which would allow reducing the cost of production and improving product quality. 


\section{Literature review and problem statement}

According to its chemical composition, castor oil is a complex multi-component system. It contains mostly complex ethers of glycerin and fatty acids, as well as the substances that can be dissolved in them. Freshly pressed oil contains impurities that reduce its quality and market appearance, as well as free fatty acids, phospholipids, aromatic substances. This oil cannot be used as a ready-to-use product without a technological purification process.

The quality of castor oil in addition to such features as color, transparency, and density depends on electrical indicators (specific resistance, dielectric permittivity, dielectric loss angle tangent).

The process of purification of castor oil is aimed at removing impurities that transfer from raw materials to oil during the substance pressing process that is called refinement.

One of the methods for purifying dielectric fluids is impurities removal due to the forces operating in the electric field. Paper [3] deals with electrophoresis and the deformation of a fluid drop weighed in another fluid and located in a heterogeneous alternating electric field with a constant component. These processes were considered for one drop and do not take into consideration the dependence of electrical conductivity of a suspension on the concentration of drops in case the dielectric is an emulsion. In paper [4], the dielectrophoretic motion of a drop under the influence of heterogeneous variable electric field was explored and it was shown that the velocity of the particle motion depends on the field frequency. Frequency dependence is known to be determined by the electrical properties of both a fluid and a drop. In addition, it was shown in article [5] that electro-hydrodynamic currents, the behavior of which also depends on electro-physical properties of contacting fluids, occur on the surface of separation of the drop and fluid phases. That is why from the theoretical and practical points of view, it is very important to know the dependences of specific electrical resistance and dielectric loss angle tangent in the emulsion on the concentration of dispersed phase, which are not found in papers [3-5].

The method for oil purification in the electric field of polyelectrode systems can be considered promising [6]. Under this method for purification on electrodes, vapor and gas bubbles that move towards the fluid surface along with impurities and then removed in mechanical or in other ways, are formed under the influence of dielectrophoretic force and heat. For this process to flow, water (1-2\%) is added to oil for hydration of phosphates and other high-molecular impurities of plant origin. Oil is heated up to $60-80{ }^{\circ} \mathrm{C}$ to form steam-gas bubbles from water droplets. High voltage (up to $5 \mathrm{kV}$ ) is given to electrodes. Electrodes (parallel cylinders with the diameter of $2-3 \mathrm{~mm}$ ) create a heterogeneous electric field due to which water droplets move towards the surface of electrodes where there is vaporization. This process makes it possible not only to purify oil from plant impurities but also to remove free moisture, which worsens the quality of the finished product [6]. However, the study did not reveal how the geometric parameters of the electrode system (the distance between electrodes and their length) were chosen. To do this, it is advisable to study volt-ampere characteristics of a weakly conductive liquid. This approach was used in article [7], where such characteristics were theoretically explored, but unfortunately, the obtained results do not make it possible to assess the temperature impact on volt-ampere characteristics.

In paper [8], the temperature impact on the electrical conductivity of refined sunflower oil was explored. The obtained results show a significant impact on the temperature on the electrical conductivity of oil. But the issues of the dependence of electrical conductivity (or specific resistance) on temperature for castor oil, which is characterized by much higher viscosity), remained unresolved.

It should be noted that in papers [6-8], there are no data on the impact of impurities, in particular water, on the electrical properties of oils. Research [9], which substantiated the technology for purification of vegetable oils in the electric field with preliminary hydration, does not contain these data either.

Electrical conductivity and dielectric permittivity of the "water in solar oil" emulsion in the water content range from 40 to $60 \%$ were explored in article [10]. Solar oil differs significantly in its rheological and electro-physical properties from castor oil and, in addition, the obtained results for the emulsion are limited to the specified interval of water content and fixed temperature.

In article [11], the data on the resistance of the emulsion "water in castor oil" in the temperature range from 20 to $90{ }^{\circ} \mathrm{C}$ at the water content from 0 to $2 \%$ were obtained. These results were received at low voltage $(100 \mathrm{~V})$ of DC. Taking into consideration the fact that the castor oil purification technology involves the use of high voltage (from 3 to $5 \mathrm{kV}$ ) AC, their results need refining for high voltage DC. Dependences of components of specific resistance and dielectric loss angle tangent on temperature and water content were not studied for high voltage AC.

The technological process of oil purification in the electric field [6] involves adding water and creating the "water in oil" emulsion. The data on the impact of water content on the electrical conductivity of castor oil at the high voltage both on DC and $\mathrm{AC}$ at the water content from 0 to $2 \%$ were not found in literary sources. Such data are necessary to determine the technological parameters of the process of purification in the electric field and energy indicators of the process.

Thus, analysis of literary sources revealed that for high-quality purification of castor oil, it is advisable to use hydration with subsequent removal of impurities and water in the high voltage electric field. At the same time, the resulting emulsion "water in castor oil" is significantly different in its electrical properties from non-moisturized castor oil. Attention was paid to the close problems of the water impact on the electrical conductivity of dielectric fluids in specific technical areas related to petroleum refining products, but these fluids in their rheological and electrical properties differ from castor oil. For castor oil, it was not studied how temperature and water content influence resistance in DC at high voltage, ohmic resistance, and impedance to high voltage AC and dielectric loss angle tangent.

All this suggests that it is advisable to conduct a study devoted to determining specific resistance on direct and alternating currents and dielectric loss angle tangent of the "water in castor oil" emulsion. Dependences of these parameters on temperature and water content make it possible to substantiate the technology of castor oil purification from plant impurities and water in the electric field. 


\section{The aim and objectives of the study}

The aim of this study is to determine the electric and physical properties of castor oil with different water content depending on temperature. This will make it possible to determine and substantiate the technological, structural, and energy parameters of the electrotechnological complex for castor oil purification in the electric field.

To accomplish the aim, the following tasks have been set:

- to obtain dependences of specific resistance of castor oil on the temperature at different water content for DC and AC;

- to obtain dependences of dielectric loss angle tangent of the "water in castor oil" emulsion on the temperature at different water content.

\section{Materials, equipment, and procedure of research}

4.1. The studied materials and equipment used in the experiment

Purified castor oil and water were used in the experimental studies. The mixer Homogenizer MPV-302 (Republic of Bulgaria) was used to obtain a stable emulsion when mixing water with oil.

The studies were conducted in a thermally insulated chamber (1) with a volume of $0.1 \mathrm{dm}^{3}$ (Fig. 1). The chamber has a cylindrical shape and consists of three electrodes: high-voltage, measuring, and protective [12].

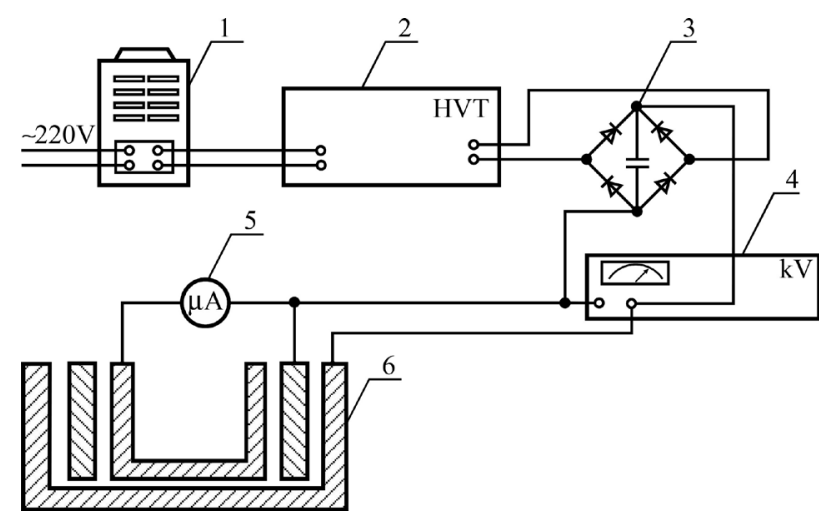

Fig. 1. The circuit of laboratory plant to study electrical properties of castor oil

High voltage AC and DC current were sent to the electrodes of the measuring chamber (6). To increase the voltage of the network, we used a high-voltage transformer TSV3-1020 (2), which was connected to the network through a laboratory autotransformer (1) to regulate voltage. During the studies on DC, a rectifying diode shunt (3) with a capacitor for pulsation smoothing was connected to the secondary winding of a high-voltage transformer.

Electrostatic kilovoltmeter C-196 (4) was used to record and measure the voltage values. The values of current power were recorded by microampermeter F195 (5).

The camera was placed in a thermo-chamber. The temperature values were recorded by a mercury thermometer (not shown in Fig. 1).

\section{2. Experiment procedure}

To carry out the research, the samples of the water-oil emulsion with a water content of $0 ; 0,5 ; 1$ and $1,5 \%$ were prepared and mixed with the Homogenizer MPV-302 mixer for 1 minute.

The emulsion sample was poured into the chamber and heated up to the temperature of $20 ; 40 ; 60$; and $80^{\circ} \mathrm{C}$. At each temperature, currents at voltages on the electrodes of 2; $3 ; 4$ and $5 \mathrm{kV}$ were measured. The voltage was smoothly changed by the autotransformer. The studies were conducted on both DC and AC.

4. 3. Procedure for processing experimental data and determining the specific resistance and dielectric loss angle tangent

Experimental data were processed and specific resistance and dielectric loss angle tangent were determined based on the parallel equivalent scheme of lossy dielectric [13, 14], which included in parallel connected capacitor and active resistors to losses. The magnitude of the capacitor is determined by the polarization of the dielectric. The ohmic resistance of liquid low-polar dielectric includes connected in a parallel resistor of end-to-end electric conductivity of castor oil and the resistor, which is caused by structural polarization in the presence of impurities of water as polar liquid.

The magnitude of impedance of the replacement circuit is calculated according to the following formula:

$$
Z_{A}=\frac{U_{A}}{I_{A}}
$$

where $Z_{A}$ is the impedance, $\mathrm{Ohm} ; U_{A}$ is the $\mathrm{AC}$ voltage on the electrodes, $\mathrm{V} ; I_{A}$ is the $\mathrm{AC}, \mathrm{A}$.

Resistance of end-to-end electric conductivity can be measured on DC and computed from the following formula:

$$
R_{t . c .}=\frac{U_{t . c .}}{I_{t . c .}}
$$

where $R_{t . c}$ is the resistance of end-to-end electric conductivity, Ohm; $U_{t . c}$ is the DC voltage on the electrodes, $\mathrm{V} ; I_{t . c}$ is the DC, A.

Equivalent resistance caused by water impurities during structural polarization and by end-to-end electrical conductivity, according to the parallel equivalent circuit, if polarization capacitance is known, can be computed from the following formula:

$$
R_{\text {e.t.c. }}=\frac{1}{\sqrt{\left(\frac{I_{A}}{U_{A}}\right)^{2}-\left(\omega \cdot C_{p}\right)^{2}}},
$$

where $R_{\text {e.t.c }}$ is the equivalent resistance of end-to-end electric conductivity and polarization losses, Ohm; $\omega$ is the angular frequency of $\mathrm{AC}, \mathrm{rad} / \mathrm{s} ; C_{p}$ is the polarization capacitance, $\mathrm{F} / \mathrm{m}$.

Resistance is caused by polarization losses:

$$
R_{p . l .}=\frac{R_{\text {e.t.c }} \cdot R_{\text {t.c. }}}{R_{\text {t.c. }}-R_{\text {e.t.c. }}}
$$

To determine specific resistance of fluid in the system of cylindrical electrodes according to the known resistance, we used the following formula:

$$
Z=k \cdot z
$$


where $Z$ is the complex resistance, Om; $z$ is the complex specific resistance, Ohm $\cdot \mathrm{m} ; k$ is the geometric coefficient of electrode shape, $\mathrm{m}^{-1}$.

For the equivalent parallel circuit, if the active component of specific resistance is much larger than the capacitive component, the geometric coefficient of the shape of the electrodes can be determined from the following formula:

$$
k=\frac{U_{A} \cdot w \cdot \varepsilon_{D . C .}}{I_{A}}=Z_{A} \cdot w \cdot \varepsilon_{D . C .},
$$

where $\varepsilon_{D . C}$ is the dielectric permittivity of oil, $\mathrm{F} / \mathrm{m}$.

The magnitude of dielectric loss angle tangent was computed from the following formula:

$$
\operatorname{tg} \delta=\frac{1}{\rho_{\text {e.t.c. }} \cdot w \cdot \varepsilon_{D . C .}} .
$$

For pure castor oil at the temperature of $20^{\circ} \mathrm{C}$, dielectric permittivity makes up from $3.54 \cdot 10^{-11}$ to $3.98 \cdot 10^{-11} \mathrm{P} / \mathrm{m}$ [15], which for an angular frequency of $314 \mathrm{rad} / \mathrm{m}(50 \mathrm{~Hz})$ corresponds to specific capacitive resistance from $8 \cdot 10^{7}$ to $9 \cdot 10^{7} \mathrm{Ohm}$. Specific active resistance of castor oil, according to the data in paper [15] makes up the magnitude from $5 \cdot 10^{8}$ to $5 \cdot 10^{10} \mathrm{Ohm} \cdot \mathrm{m}$. That is why, to calculate the geometric coefficient of the electrode system, we used formula (6).

\section{Results of studying the electrical and physical properties of the "water in castor oil" emulsion}

\section{1. Results of studying the specific resistance} of the "water in castor oil" emulsion

To determine the electrical properties of the "water in castor oil" emulsion, the values of currents flowing into the system of cylindrical electrodes from the DC and AC sources of a voltage of $4 \mathrm{kV}$ were measured. The voltage of $4 \mathrm{kV}$ was selected as maximum possible for the temperature range from 20 to $80{ }^{\circ} \mathrm{C}$ and water content from 0 to $2 \%$ for a constant process without a breakdown of suspension. Table 1 shows the results for DC, and Table 2 shows the results for AC.

Table 1

$D C$ in the system of cylindrical electrodes at a voltage of $4 \mathrm{kV}$ at different values of water content and temperature of castor oil

\begin{tabular}{|c|c|c|c|c|c|}
\hline \multirow{2}{*}{ Temperature, ${ }^{\circ} \mathrm{C}$} & \multicolumn{5}{|c|}{ Current, $\mu \mathrm{A}$} \\
\cline { 2 - 6 } & $0 \%$ & $0.5 \%$ & $1 \%$ & $1.5 \%$ & $2 \%$ \\
\hline 20 & 0,4 & 10 & 20 & 50 & 150 \\
\hline 40 & 1 & 18 & 45 & 90 & 320 \\
\hline 60 & 1,7 & 30 & 70 & 130 & 460 \\
\hline 80 & 2,5 & 35 & 90 & 160 & 580 \\
\hline
\end{tabular}

The data obtained as a result of the experimental studies and presented in Tables 1, 2 are used in calculations of resistances on alternating and direct currents and dielectric loss angle tangent.

To calculate specific resistances (1)...(5), the values of the geometric coefficient of the electrodes' shape were previously calculated. To do this, the value of current in pure castor oil at the temperature of $20^{\circ} \mathrm{C}$ and at the voltage on the electrodes of $2,3,4$, and $5 \mathrm{kV}$ were measured. Calculation of capacitive resistance according to formula (1) gave the average magnitude $Z_{A}=121 \mathrm{MOhm}$ and the corresponding value of the coefficient of electrodes' shape according to formula (6) (for the average dielectric permittivity of oil $\left.\varepsilon_{D . C .}=3.76 \cdot 10^{-11} \mathrm{~F} / \mathrm{m}\right) k=1.43 \mathrm{~m}^{-1}$.

Table 2

$\mathrm{AC}$ in the system of cylindrical electrodes at a voltage of $4 \mathrm{kV}$ at different values of water content and temperature of castor oil

\begin{tabular}{|c|c|c|c|c|c|}
\hline \multirow{2}{*}{ Temperature, ${ }^{\circ} \mathrm{C}$} & \multicolumn{5}{|c|}{ Current, $\mu \mathrm{A}$} \\
\cline { 2 - 6 } & $0 \%$ & $0.5 \%$ & $1 \%$ & $1.5 \%$ & $2 \%$ \\
\hline 20 & 30.01 & 31.83 & 36.91 & 61.77 & 165.5 \\
\hline 40 & 30.04 & 35.6 & 56.92 & 101.7 & 348.5 \\
\hline 60 & 30.1 & 43.83 & 81.01 & 143.6 & 500 \\
\hline 80 & 30.2 & 47.85 & 101.3 & 175.4 & 630 \\
\hline
\end{tabular}

The results of calculations of specific resistance on AC in the form of graphical dependences are shown in Fig. 1, 2. Impedance does not depend on temperature for castor oil without adding water. If there is water in oil, the specific resistance of end-to-end electrical conductivity decreases at an increase in temperature and an increase in water content.

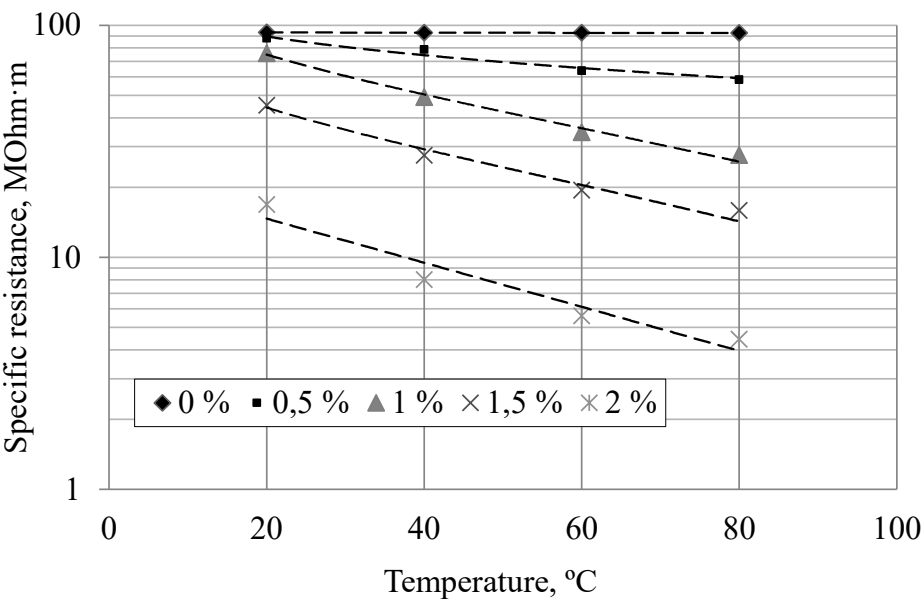

Fig. 2. Dependences of specific resistance on $A C$ of castor oil with various water content on the temperature at a frequency of $50 \mathrm{~Hz}$

To determine energy characteristics of the process of oil purification in the electric field, the equivalent active specific resistance of oil, which causes heat release according to the Joule-Lenz law and the magnitude of dielectric losses angle tangent are of interest. To calculate its magnitude, we used (3). Corresponding graphic dependences are shown in Fig. 3.

Analysis of these dependences revealed that active specific resistance at the water content of $0 \%$ within the entire temperature interval is much higher than the capacitive resistance of $121 \mathrm{MOhm}$. At the water content of $0.5 \%$ and the temperature of about $60{ }^{\circ} \mathrm{C}$, these resistances are comparable. At an increase in temperature over $60^{\circ} \mathrm{C}$, active resistance to water content from 1 to $2 \%$ becomes determining, that is smaller, within the entire interval of temperatures active specific resistance is much lower than capacitive resistance.

To identify the specific features of the oil purification process in a constant electric field, the values of specific resistance to DC were calculated according to formula (2). The obtained data also enabled further determining active resistance, caused by structural polarization in the presence of water impurities. Corresponding dependences are shown in Fig. 4. 


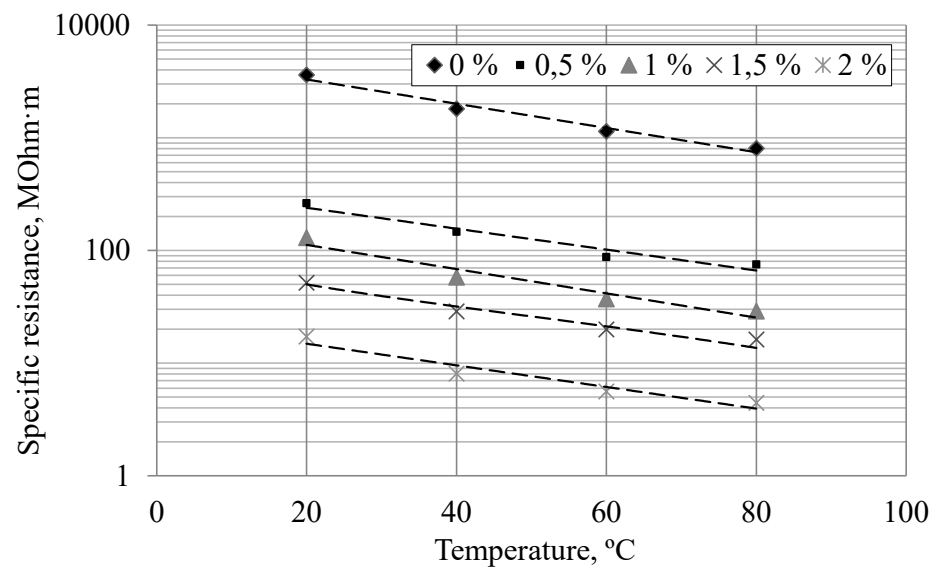

Fig. 3. Dependences of the active component of specific resistance on AC of castor oil with various water content on the temperature at a frequency of $50 \mathrm{~Hz}$

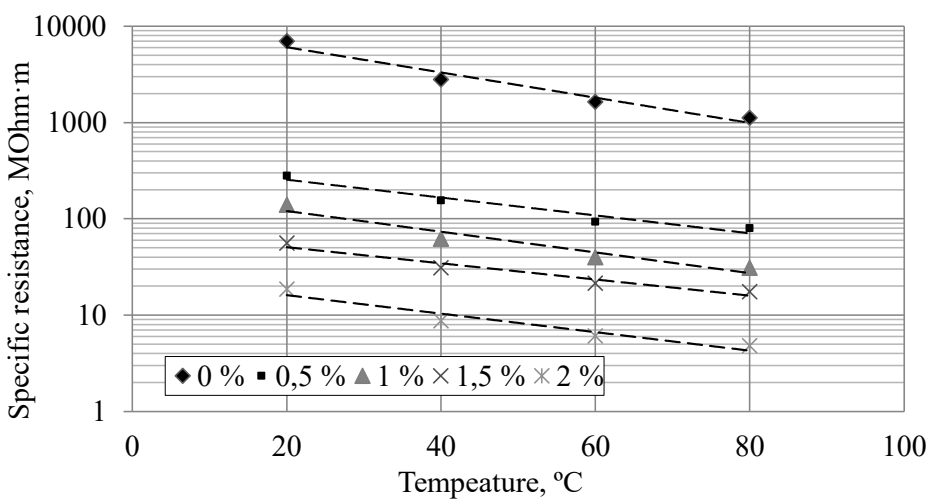

Fig. 4. Dependences of specific resistance of castor oil with different water content on temperature on DC (end-to-end electric conductivity)

It follows from these dependences that specific resistance to DC significantly depends not only on temperature but also on water content. Thus, at a change in water content from 0 to $2 \%$, specific resistance to DC is reduced by $200 \ldots 300$ times.

In order to identify how resistances on DC and AC are related, the magnitudes of specific active resistance of polarization losses (4) were calculated and corresponding graphic dependences were constructed (Fig. 5).

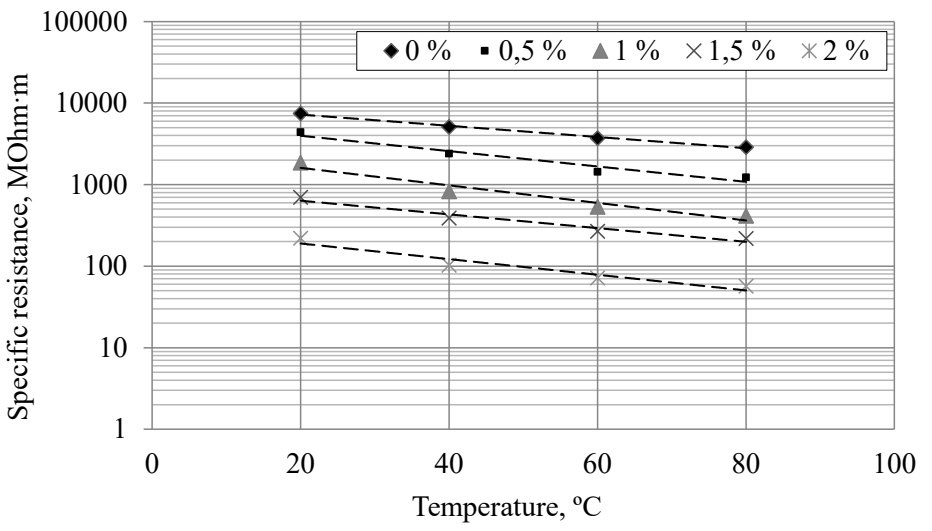

Fig. 5. Dependences of specific resistance of polarization losses of castor oil with different water content on the temperature at a frequency of $50 \mathrm{~Hz}$
Graphic dependences in Fig. 5 show that resistances of polarization losses of the "water in castor oil" emulsion are higher than resistances of end-to-end electrical conductivity on DC (Fig. 4). Depending on the temperature and water content, this difference is from 100 to $1,000 \%$. When adding water and raising the temperature, this difference increases.

5. 2. Results of studying dielectric loss angle tangents of the "water in castor oil" emulsion

On AC, polarizing losses, which are commonly characterized by dielectric loss angle tangents, or the angle tangent, are added to the losses of end-to-end electrical conductivity That is why we constructed graphic dependences of dielectric loss angle tangent on temperature and water content (Fig. 6, 7).

Dependences of Fig. 6 show that at water content from $0 \%$ to $2 \%$, the impact of temperature on losses in oil is insignificant (when the temperature increases from 20 to $80^{\circ} \mathrm{C}$, losses increase by $3 \ldots 5$ times).

It follows from dependences in Fig. 7 that at an increase in water content, dielectric losses significantly increase. Thus, at a change in water content from 0 to $2 \%$ at the temperature of $20{ }^{\circ} \mathrm{C}$, losses increase by 216 times, at the temperature of $40{ }^{\circ} \mathrm{C}-$ by 230 times, at the temperature of $60{ }^{\circ} \mathrm{C}-$ by 208 times, and at the temperature of $80^{\circ} \mathrm{C}-$ by 174 times. 


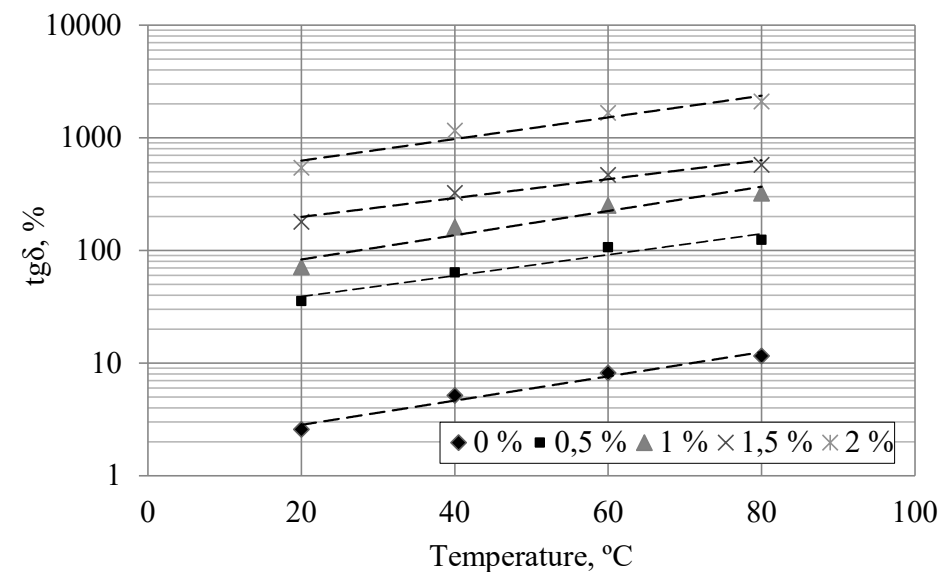

Fig. 6. Dependences of dielectric loss angle tangent of castor oil with different water content on the temperature at a frequency of $50 \mathrm{~Hz}$

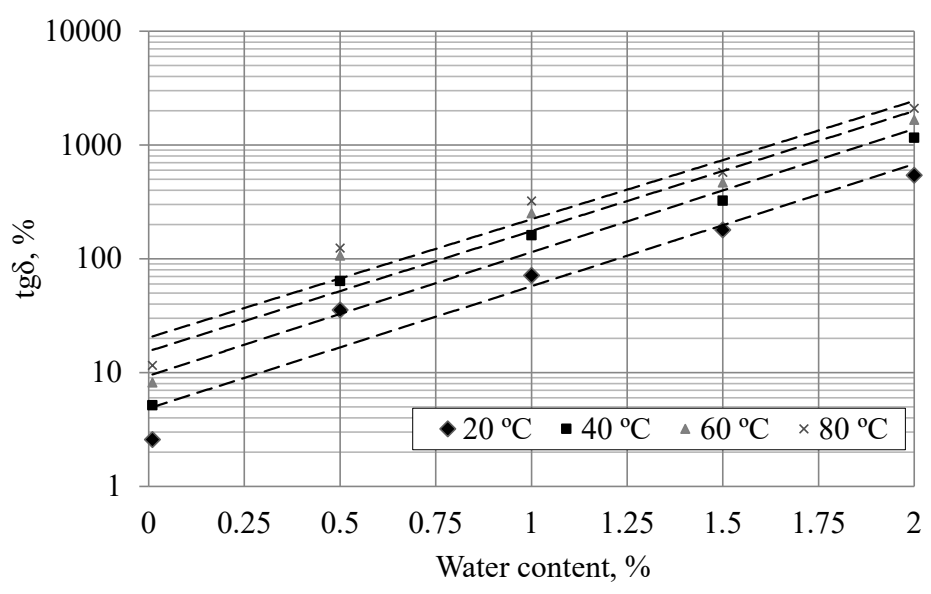

Fig. 7. Dependences of dielectric loss angle tangent of castor oil with various water content on the temperature at a frequency of $50 \mathrm{~Hz}$

\section{Discussion of results of studying the electrical properties of the "water in castor oil" emulsion}

Experimental results proved the assumption that specific resistance of pure, without any impurities, castor oil is determined by a capacitive resistance of polarization. It should be noted that according to Fig. 2, 3, they differ almost by two orders of magnitude, which substantiates the reliability of the determined geometric coefficient of the electrodes' shape by the magnitude of the impedance of oil.

To evaluate the electrical properties of the "water in castor oil" emulsion, it is advisable to compare the components of specific resistance at a change in water content and temperature. This is important both in terms of energy consumption for the oil purification process in the electric field and for analysis of the mechanism of this process.

If the process is carried out on DC (Fig. 4), for which the emulsion "water in the castor oil" has much higher specific resistance within the entire interval of temperatures, respectively, heat release will be less than when using AC (Fig. 3). This can be explained based on the parallel equivalent circuit of lossy dielectric $[13,14]$. On DC, resistance included only resistance of end-to-end electrical conductivity, and on $\mathrm{AC}$, the resistance of polarization losses is connected in parallel to this resistance. As a result, the impedance to AC decreases.

It should be noted that the vaporization process in the emulsion under the influence of the electric field determines the quality of the flotation purification of castor oil and it should be stable. And for this, local heat release in the electrode region plays a significant role. From this point of view, AC is more suitable for obtaining vapor-gas flotation bubbles.

A comparison of the magnitudes of polarization losses and losses of end-to-end electrical conductivity for pure oil indicates their identical order, and the addition of water leads to a significant increase in both losses due to end-to-end electrical conductivity and to polarization losses. An increase in end-to-end electrical conductivity is explained by both ion electric conductivity and an increase in the number of electrophoretic water particles and their deformation in the electric field [3, 4], and an increase in polarization losses is explained by the structural and dipolar polarization of water as a polar fluid $[13,14,16]$. Due to this, from the theoretical point of view, we can talk about local additional heat release on finely dispersed drops of water in the quantity, which can provide compensation for the heat needed for vaporization. Thus, the boiling maintaining process and obtaining enough vapor bubbles does not require indirect heating of the electrode area from an external source due to thermal conductivity.

On the other hand, heat release in the dielectric emulsion under the influence of alternating electric field is characterized by the magnitude of dielectric loss angle tangent. This indicator for both pure castor oil and for the emulsion "water in castor oil", depends on the temperature and its increase almost by 5 times at an increase in temperature from 20 to $80^{\circ} \mathrm{C}$ is determined by a decrease in specific resistance (second king electric conductivity of oil as a weakly polar liquid), electrophoretic electric conductivity and an increase in losses in dipole polarization [13,14].

The obtained results do not differ from the data on the temperature impact on pure castor oil known from papers [15]. Regarding the impact of water on specific resistance and dielectric loss angle tangent, the literature contains the data only for low water content (up to $0.5 \%$ ), and in this case, water is partially dissolved in oil and does not affect specific resistance. That is why in contrast to the data $[10,17]$, the range of water content in the oil, in which dielectric losses were studied, was significantly expanded. This made it possible to determine the electrical properties of oil to substantiate electrical-technological and energy parameters of the purification process in the electric field: the magnitude of power voltage and the kind of current, number, and length of electrodes, treatment time, energy consumption, active and full powers.

The studies of the electro-physical properties of the "water in castor oil" emulsion were conducted at a fixed voltage on $4 \mathrm{kV}$ electrodes, which corresponds to the technological parameters of the oil purification process in the electric field. It is advisable to conduct these studies in the direction of identification of dependences of specific resistances and dielectric voltage loss angle tangent. In addition, for the technology of castor oil purification, it is important to know the dependences of the voltage of the electrical breakdown of the suspension on temperature and water content. 


\section{Conclusions}

1. The conducted studies established the dependences of specific resistance on direct and alternating currents and dielectric loss angle tangent of castor oil on temperature and water content. A comparison of these dependences suggests that heat release in the "water in castor oil" emulsion at the same temperature and water content on $\mathrm{AC}$ exceeds heat release on direct current. At the temperature of $80{ }^{\circ} \mathrm{C}$ and water content of $2 \%$, heat release on $\mathrm{AC}$ exceeds the heat release on the direct current by $10 \%$.

2. It is reasonable to perform the process of castor oil purification from plant impurities on AC, which makes it possible to get additional heat release and thereby compensate for heat losses for the vaporization of flotation bubbles, leading to the stable process of flotation purification.

\section{Acknowledgment}

The work was carried out in accordance with the program of scientific and technical research of Tavria State Agrotechnological University named after Dmytro Motornyi "Science in TSATU" for 2016-2020 on the following themes:

1. "Development of energy-saving electrical technologies and devices to increase the productivity and quality of agricultural biological sites with the use of electromagnetic fields of different spectral range", state registration number 0116 U002722.

2. "Development of technology and devices for purification and control over contamination of irrigation water, working and lubricating fluids", state registration number $0116 \mathrm{U} 002743$.

\section{References}

1. Chinchkar, D. S., Satpute, S. T., Kumbhar, N. R. (2012). Castor Oil as Green Lubricant: A Review. International Journal of Engineering Research \& Technology (IJERT), 1 (5). Available at: https://www.ijert.org/research/castor-oil-as-green-lubricant-areview-IJERTV1IS5236.pdf

2. Kushlyk, R., Nazarenko, I., Kushlyk, R., Nadykto, V. (2017). Research into effect of ultrasonic, electromagnetic and mechanical treatment of blended biodiesel fuel on viscosity. Eastern-European Journal of Enterprise Technologies, 2 (1 (86)), 34-41. doi: https://doi.org/10.15587/1729-4061.2017.95985

3. Supeene, G., Koch, C. R., Bhattacharjee, S. (2008). Deformation of a droplet in an electric field: Nonlinear transient response in perfect and leaky dielectric media. Journal of Colloid and Interface Science, 318 (2), 463-476. doi: https://doi.org/10.1016/ j.jcis.2007.10.022

4. Thaokar, R. M. (2012). Dielectrophoresis and deformation of a liquid drop in a non-uniform, axisymmetric AC electric field. The European Physical Journal E, 35 (8). doi: https://doi.org/10.1140/epje/i2012-12076-y

5. Tarantsev, K. V. (2010). Study of electrohydrodynamic flows at a liquid-liquid phase interface. Chemical and Petroleum Engineering, 46 (1-2), 64-68. doi: https://doi.org/10.1007/s10556-010-9292-y

6. Didur, V. V., Didur, V. A., Nazarenko, I. P., Nazarova, O. P., Didenko, O. V (2018). Modeling of the process of purification press castor oil by flotation method. Machinery \& Energetics. Journal of Rural Production Research, 9 (3), 91-96. Available at: http:// www.tsatu.edu.ua/ettp/wp-content/uploads/sites/25/statja-2.pdf

7. Stishkov, Yu. K., Chirkov, V. A., Sitnikov, A. A. (2014). Dinamicheskie vol't-ampernye harakteristiki slaboprovodyashchih zhidkostey v sil'noneodnorodnyh elektricheskih polyah. Elektronnaya obrabotka materialov, 50 (2), 35-40. Available at: http:// eom.phys.asm.md/ru/journal/shortview/1039

8. Beril I. I., Bologa, M. K. (2010). Temperaturnaya zavisimost' elektroprovodnosti slaboprovodyashchih organicheskih gidkostey. Elektronnaya obrabotka materialov, 46 (3), 43-44. Available at: http://eom.phys.asm.md/ru/journal/shortview/543

9. Todorov, V. G., Aprahamian, B. R., Tahrilov, H. P. (2015). Opportunities for application of elecrotechnological methods when processing vegetable oils. Conference: 14th International conference of electrical machines, drives and power systems ELMA 2015. Varna. Available at: https://www.researchgate.net/publication/296846046_Opportunities_for_application_of_ electrotechnological_methods_when_processing_vegetable_oils

10. Tarasova, G. I., Shevaga, O. N., Tarasov, V. V., Gracheva, E. O., Haertdinova, A. A. (2015). Issledovanie reologicheskih i elektricheskih svoystv obratnyh emul'siy, stabilizirovannyh termoliznym defekatom TD 600. Vestnik Kazanskogo tehnologicheskogo universiteta, 18 (6), 90-93. Available at: https://cyberleninka.ru/article/n/issledovanie-reologicheskih-i-elektricheskih-svoystv-obratnyhemulsiy-stabilizirovannyh-termoliznym-defekatom-td-600/viewer

11. Nazarenko, I., Didenko, O., Loboda, O., Dubinina, S. (2019). The influence of temperature and moisture on the electrophysical properties of castol oil. Naukovyi visnyk Tavriyskoho derzhavnoho ahrotekhnolohichnoho universytetu imeni Dmytra Motornoho, 1 (10). Available at: http://elar.tsatu.edu.ua/bitstream/123456789/11322/1/28.\%20\%D0\%9D\%D0\%B0\%D0\%B7\%D0\%B0\%D1\% $80 \% \mathrm{D} 0 \% \mathrm{~B} 5 \% \mathrm{D} 0 \% \mathrm{BD} \% \mathrm{D} 0 \% \mathrm{BA} \% \mathrm{D} 0 \% \mathrm{BE} \cdot \mathrm{pdf}$

12. GOST 6581-75. Materialy elektroizolyatsionnye zhidkie. Metody elektricheskih ispytaniy (2008). Moscow: Izd-vo standartov, 16.

13. Poplavko, Yu. M.; Yakymenko, Yu. I. (Ed.) (2015). Fizyka dielektrykiv. Kншм: NTUU «KPI», 572.

14. Efendiev, O. F. (1977). Elektroochistka zhidkosti v pishchevoy promyshlennosti. Мщысщщ: Pishchevaya promyshlennost', 149

15. Kikoina, I. K. (Ed.) (1976). Tablitsy fizicheskih velichin. M.: Atomizdat, 1008.

16. Nazarov, N. K. et. al. (1989). Osobennosti obrazovaniya struktur v emul'siyah obratnogo tipa pod deystviem peremennyh elektricheskih poley. Izvestiya Akademii nauk Kazahskoy SSR, 2, 32-37.

17. Koval', A. V., Vildanov, R. R., Gaynullina, L. R., Sidorenko, A. V., Tutubalina, V. P. (2005). The influence of some factors on exploitationable properties of transformer's. Izvestiya vysshih uchebnyh zavedeniy. Problemy energetiki, 1-2, 100-104. 